\title{
Double Allee Effects and Extinction in the Island Fox
}

\author{
ELENA ANGULO ${ }^{*}+\dagger$ GARY W. ROEMER,† LUDĚK BEREC,† JOANNA GASCOIGNE,§ \\ AND FRANCK COURCHAMP*
}

${ }^{*}$ Ecologie, Systématique et Evolution, UMR CNRS 8079, University of Paris-Sud, Orsay Cedex 91405, France

†Department of Fishery and Wildlife Sciences, New Mexico State University, P.O. Box 30003, MSC 4901, Las Cruces, NM 88003-8003, U.S.A.

†Department of Theoretical Ecology, Institute of Entomology, Biology Centre ASCR, Branišovská 31, 37005 České Budějovice, Czech Republic

$\S$ School of Ocean Sciences, University of Wales, Bangor, Menai Bridge, Anglesey, LL59 5AB, United Kingdom

\begin{abstract}
An Allee effect (AE) occurs in populations when individuals suffer a decrease in fitness at low densities. If a fitness component is reduced (component AE), per capita population growth rates may decline as a consequence (demographic AE) and extinction risk is increased. The island fox (Urocyon littoralis) is endemic to six of the eight California Channel Islands. Population crashes have coincided with an increase in predation by Golden Eagles (Aquila chrysaetos). We propose that AEs could render fox populations more sensitive and may be a likely explanation for their sharp decline. We analyzed demographic data collected between 1988 and 2000 to test whether fox density (1) influences survival and reproductive rates; (2) interacts with eagle presence and affects fox fitness parameters; and (3) influences per capita fox population trends. A double component AE simultaneously influenced survival (of adults and pups) and proportion of breeding adult females. The adult survival AE was driven by predation by eagles. These component AEs led to a demographic AE. Multiple-component AEs, a predation-driven AE, and the simultaneous occurrence of both component and demographic AEs in a mammal are all previously unreported processes. Populations below 7 foxes $/ \mathrm{km}^{2}$ could have suboptimalpopulation growth rates due to the demographic AE, and AEs may have contributed to the dramatic declines in three fox populations. Because fox densities in critically endangered populations are well below this level, removing Golden Eagles appears necessary to prevent a predation-driven AE. Conservationists should also be aware of AEs when planning the release of captive foxes. More generally, our findings highlight the danger of overlooking AEs in the conservation of populations of rare or threatened species.
\end{abstract}

Keywords: Allee effect, Aquila chrysaetos, Golden Eagle, inverse density dependence, island fox, positive density dependence, predation-driven Allee effect, Urocyon littoralis

Efectos Allee Dobles y Extinción en Urocyon littoralis

Resumen: Un efecto Allee (EA) ocurre en una población con baja densidad cuando la adaptabilidad de los individuos decrece. Si un componente de la adaptabilidad (EA componente) disminuye, las tasas de crecimiento poblacional per capita pueden disminuir como una consecuencia (EA demográfico) y el riesgo de extinción incrementa. Urocyon littoralis es un zorro endémico de seis de las ocho Islas del Canal de California. Los colapsos de la población han coincidido con un incremento en la depredación por águilas doradas (Aquila chrysaetos). Proponemos que los EA pueden hacer que las poblaciones de zorros sean más sensibles y que pueden ser una explicación para su marcada declinación. Analizamos datos demográficos recolectados entre 1998 y 2000 para probar sí la densidad de zorros (1) influye en la supervivencia y en las tasas reproductivas; (2) interactúa con la presencia de águilas y afecta los parámetros de adaptabilidad de los zorros; y (3) influye en las tendencias poblacionales per cápita. Un EA con dos componentes influyó simultáneamente en la supervivencia (de adultosy cachorros) y en la proporción de hembras reproductivas. El EA de supervivencia de adultos fue dirigido por depredación por águilas. Estos EA componentes condujeron a un AE demográfico.

\#emailelena.angulo@u-psud.fr

Paper submitted August 3, 2006; revised manuscript accepted January 12, 2007. 

Los EA con componentes múltiples, un AE dirigido por la depredación y la ocurrencia simultánea de EA componentes y demográficos son procesos no reportados previamente en mamíferos. Las poblaciones con menos de 7 zorros $/ \mathrm{km}^{2}$ podrian tener crecimiento poblacional subóptimo debido al EA demográfico, y los EA pueden haber contribuido a las declinaciones dramáticas en tres poblaciones de zorros. Debido a que las densidades de zorros en poblaciones en peligro crítico están muy debajo de este nivel, parece ser necesario remover águilas doradas para prevenir un EA dirigido por la depredación. Los conservacionistas también deben tener cuidado de los EA cuando se planifique la liberación de zorros cautivos. Más generalmente, nuestros hallazgos resaltan el peligro de no considerar los EA en la conservación de poblaciones de especies raras o amenazadas.

Palabras Clave: águila dorada, Aquila chrysaetos, denso dependencia inversa, denso dependencia positiva, efecto Allee, efecto Allee debido a la depredación, Urocyon littoralis

\section{Introduction}

An Allee effect (AE) occurs when individuals within a population experience a decrease in fitness, such as a decrease in reproduction and/or survival, at low population densities (Courchamp et al. 1999; Stephens et al. 1999). Therefore, an AE refers strictly to positive density dependence at low population densities. This effect is also called inverse density dependence (depensation in the fisheries literature). In contrast, classical negative density dependence predicts individual fitness to be highest at low densities and lowest at high densities owing to the negative effects of overcrowding. Mechanisms giving rise to AEs often involve social or cooperative processes among conspecifics, such that individuals do better collectively than alone (Courchamp et al. 2002).

Although AEs are manifested in some component of individual fitness, they may have repercussions for the population as a whole. Stephens et al. (1999) differentiate between component AEs, which occurs when there is a reduction in a component of individual fitness (e.g., survival, reproduction) at low density levels, and demographic AEs, which occur at the population level via the per capita population growth rate. Reduction of some measurable component of individual fitness could lead to a reduction in per capita population growth rate, but a component AE will not systematically produce a demographic AE.

The AE typically arises via mechanisms, such as cooperation or reproductive behavior, that are intrinsic to the species' life history (Courchamp et al. 1999). Cantrell et al. (2001) describe how predators theoretically could cause a component AE by increasing per capita predationdriven mortality at low densities. This predation-driven $\mathrm{AE}$ is a type of component AE that affects survival. This type of $\mathrm{AE}$ is externally driven, rather than intrinsic to the species. A predation-driven AE would only be exhibited in a prey population when the predator-prey relationship takes particular forms (Gascoigne \& Lipcius 2004a). Predator-prey relationships are classically divided into a numerical response (variation in predator density as a function of prey density) and a functional response (variation in predator consumption rate as a function of prey density). Functional response patterns are typically classified as linear (type I), saturating (type II), or sigmoidal (type III). Theory suggests that a predation-driven $\mathrm{AE}$ in individual survival is possible when the numerical response of the predator is limited and the functional response is type II; that is, predator consumption increases at a decreasing rate with increasing prey density, implying that at low prey density prey survival rates are the lowest (Fig. 1). The extrinsic characteristic of the predationdriven AE has important ramifications for conservation and management because the control of a predator would eliminate this component AE.

We provide evidence of multiple AEs based on analyses of population trends in the island fox, Urocyon littoralis, a critically endangered carnivore. The island fox is endemic to six of the eight California Channel Islands (Fig. 2a). Population crashes recently occurred on the three northern islands (Fig. 2b) and led to the extinction of wild populations on San Miguel and Santa Rosa islands and to a dramatic decline in the fox population $(>90 \%$ in 10 years) on Santa Cruz Island (Coonan et al. 2005). The onset of these crashes coincided with the colonization of these islands by Golden Eagles (Aquila chrysaetos), an event facilitated by the proximity of northern islands to mainland California (Fig. 2a) and by the abundance of a reliable source of prey, introduced feral pigs (Sus scrofa). Golden Eagles also preyed heavily on the unwary fox, causing a rapid decline in the native fox populations inhabiting these islands (Roemer et al. 2001a, 2002).

We propose that AEs are a likely explanation for the sharp decline that occurred in the fox populations on the northern islands and that they take place through different mechanisms. First, a component AE in reproduction could arise from a scarcity of mating opportunities at low population densities that could lead to a reduction in the per capita reproductive output (Berec et al. 2001). Monogamous, long-lived species are especially likely to suffer from a component AE in reproduction (Saether et al. 1996). Island foxes are distributed as mated pairs 


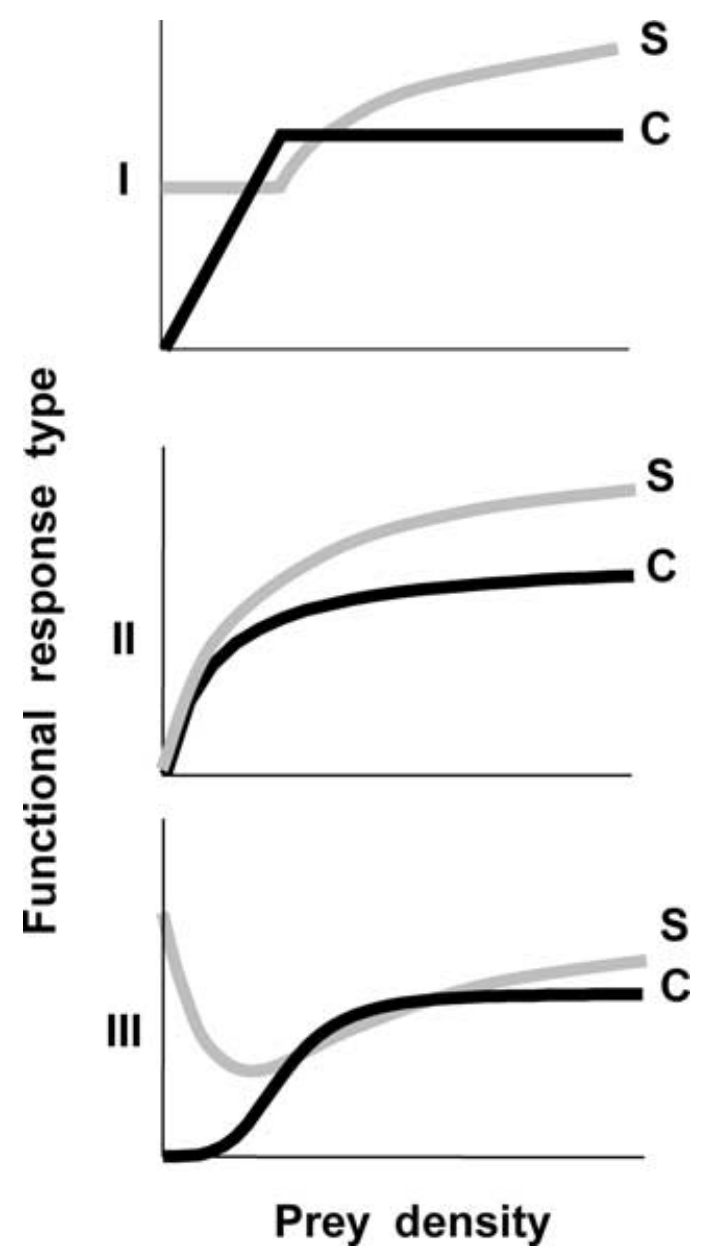

Figure 1. Three classical types of predator functional response to prey density: rate of predator consumption (C) and resulting individual survival probability of prey (S) as functions of prey density. Modified from Gascoigne and Lipcius (2004a).

that maintain discrete territories. The pair bonds for life, and although there is little overlap between the territories of neighboring pairs, extrapair copulations do occur occasionally (Roemer et al. 2001b). Mature offspring often disperse short distances to neighboring territories and may live within their natal territory for an extended time. At high densities the loss of a mate can be filled by offspring of neighboring territories; at low densities the distance between territories increases, reducing the likelihood that offspring will find and pair with widowed individuals (Roemer et al. 2001b). The loss of a mate also can induce territory instability and reduces reproductive output for some individuals (Roemer 1999). Opportunities for extrapair copulations also are reduced at low densities because there are fewer neighbors. Thus, low fox densities could hinder the possibility of finding a mate and thus diminish the production of pups, triggering a component $\mathrm{AE}$ in reproduction.

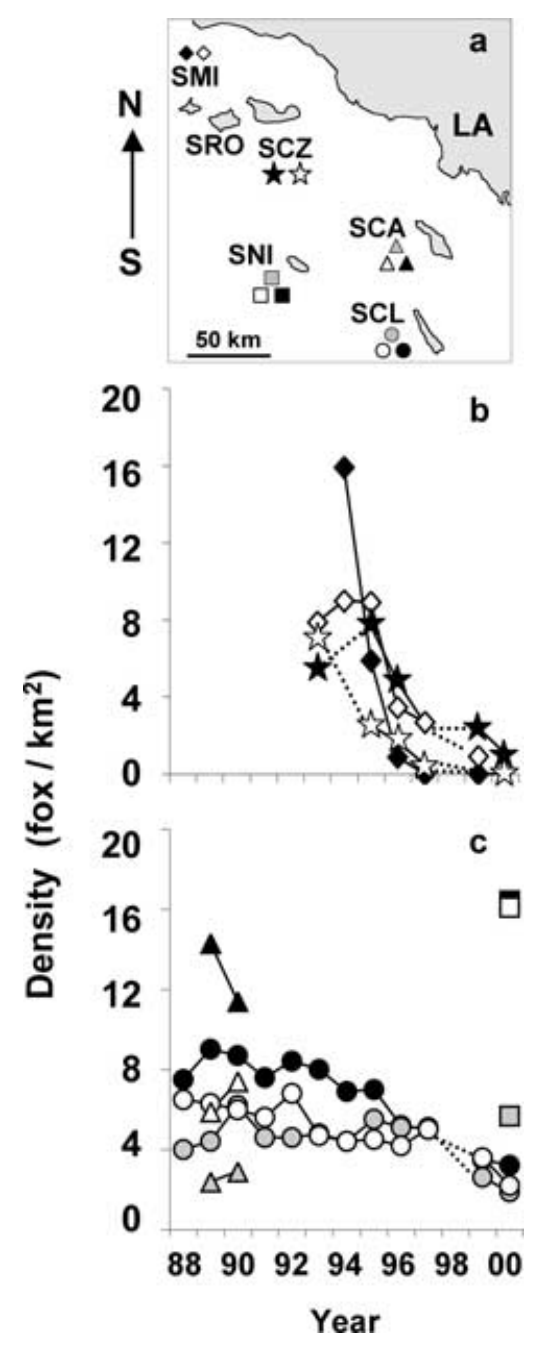

Figure 2. (a) Location of study islands: Santa Rosa (SRO), Santa Cruz (SCZ), and San Miguel (SMI) in the north; Santa Catalina (SCA), San Clemente (SCL), and San Nicolas (SNI) in the south (LA, Los Angeles; symbols represent different populations on each island). Changes in density over time in (b) northern and (c) southern island fox populations. Dotted lines represent populations in years without data.

Second, Golden Eagles could cause a predation-driven AE. Prior work revealed that following colonization Golden Eagles became the only predator and the main cause of mortality of island foxes inhabiting the northern islands (Roemer et al. 2001a, 2002). Although it is recognized that Golden Eagles were a major factor in the decline of island fox populations, a predation-driven $\mathrm{AE}$ in fox survival caused by Golden Eagles can only be shown if the per capita mortality rate caused by Golden Eagles is higher at low fox density. If this relationship exists, a predation-driven AE could potentially accelerate the extinction of fox populations. 
The hypothesis of a type II functional response of eagles with no numerical response to fox density is supported by two lines of evidence. First, eagles continue to prey on foxes even at low densities of foxes (the hallmark of a type II functional response). The first Golden Eagle nest for the Channel Islands discovered in 1999 on Santa Cruz Island contained remains of foxes (Roemer et al. 2001a), even though fox abundance was already very low (Fig. 2b). More recently, an examination of 3343 prey remains collected in 2003 from eight nests representing six territories indicates that foxes comprised from $5.4 \%$ (on Santa Cruz Island) to 8.5\% (on Santa Rosa Island) of all prey biomass (Collins \& Latta 2006). Foxes were the forth or fifth most important prey item by biomass on Santa Cruz and Santa Rosa islands, respectively. Because nests had several layers, prey remains represented the whole life span of the nest-from at least 1999 to 2003, when fox abundance was already low. This means eagles did not reduce their intake of island foxes as fox density decreased.

Second, introduced pig populations, not fox populations, sustain the permanent presence of eagles in the northern islands, and thus, pigs rather than foxes, create the numerical response. Models of predation by Golden Eagles on foxes in the presence or absence of a feral pig population showed that a fox population, unlike a pig population, cannot sustain an eagle population (Roemer et al. 2002). Only the presence of pigs explained the number of eagles and their permanence on the islands. Eagle numbers remained high despite low fox numbers. Between November 1999 and June 2006, 45 Golden Eagles were removed from the northern islands, and 7-10 eagles resided continuously on these islands until June 2004 (Latta 2005; Coonan \& Dennis 2006; Swarts 2006; V. Bakker, personal communication). During this time there were no foxes on San Miguel and Santa Rosa islands, and there were approximately 100 on Santa Cruz Island.

One or both of these component AEs (predation-driven $\mathrm{AE}$ or a component $\mathrm{AE}$ in reproduction) if present could have been sufficiently strong to create a demographic AE that could have precipitated the near extinction of the fox populations. We tested for the existence of a demographic $\mathrm{AE}$ in the island fox and analyzed the mechanisms that could have caused it. We searched for multiple component AEs and examined whether these component AEs could have been driven by predation by Golden Eagles.

\section{Methods}

\section{Field Data}

We analyzed time-series data from 13 trapping grids distributed among five islands where fox populations were monitored (Fig. 2). Fox populations were censused annually following a birth pulse (June-August) with a capture- mark-recapture approach (Roemer et al. 2001a). Population density was estimated every year with closedpopulation models in the program CAPTURE(http:// www.warnercnr.colostate.edu/ gwhite/software.html). Because we used trapping grids of different sizes, we estimated density by dividing the estimate of population size by the effective trapping area. The latter was based on the mean maximum distance moved (MMDM). The MMDM is the average of the maximum distance between captures for individuals captured two or more times. Half of this distance was added to each side of a grid to estimate the effective trapping area (Wilson \& Anderson 1985; Roemer et al. 2000). We calculated per capita population growth rate as a relative increase in population density (D) between 2 consecutive years $(t)$, $D_{t+1} / D_{t}$ (Liebhold \& Bascompte 2003).

For each population we examined the possibility of a component $\mathrm{AE}$ in reproduction by looking at two fitness components: the proportion of breeding adult females and the number of pups per adult female. The former is a measure of the probability that a female successfully bred, whereas the latter quantifies the productivity per female. We examined these two parameters separately because if a component $\mathrm{AE}$ in reproduction is occurring it may be operating in multiple ways. First, at low densities females may lose a mate before becoming pregnant, thus reducing their probability of breeding. Second, females may also lose a mate after parturition and the mate's contribution may be necessary for pup survival (Garcelon et al. 1999); reduced female productivity would be recorded if pups died before the census was conducted. Females captured in the field were assigned to one of the following four categories corresponding to their reproductive status: inactive, pregnant, lactating, or with signs of having lactated. We calculated female productivity as the number of pups captured relative to the number of adult females captured.

We used the encounter history of individuals and the Cormack-Jolly-Seber model formulation to estimate annual apparent survival of adults and pups in the program MARK (White \& Burnham 1997). We examined survival for possible effects (i.e., time, age, grid location, and island) and selected the most robust model based on Akaike's information criterion (for details see Roemer et al. 2000). We assumed that eagles were the main cause of mortality of island foxes during the study period, based on the following. Before the arrival of Golden Eagles on Santa Cruz Island, the survival rate of radio-collared foxes over a 7-month period in 1993 was 100\%. After eagles colonized the island, fox survival dropped to $21 \%$ over the next 17 months (Roemer et al. 2001a). After exploring other possible mortality agents including disease, Roemer et al. (2001a) concluded that predation by eagles accounted for nearly $90 \%$ of all mortalities ( $n=28$ carcasses) and was consistent with the simultaneous decline in fox populations on all three northern islands. Furthermore, 
between 2000 and 2006, 72\% of 51 radio-collared foxes found dead on Santa Cruz Island were killed by Golden Eagles (Coonan \& Dennis 2006).

We used temporal and spatial distribution of Golden Eagle sightings on the California Channel Islands collected over the past 35 years to estimate the presence or absence of eagles in each population and year. Data on eagle numbers were based on anecdotal observations, not on attempts to estimate exact number of eagles (counts of eagles did not begin until 1999 [Latta 2005]). However, these data yielded good information on eagle presence or absence (for more information on these methods see Roemer et al. 2001a). Annual demographic parameters of the island fox (surveyed between June and August each year) did not exactly correspond to annual eagle sightings (recorded from January to December). For this reason, we assumed that fox demographic parameters in a year (t) (from June $t-1$ to June $t$ ) could be affected either by the presence of eagles in year $t$ or in year $t-1$. Thus, presence of eagles was considered positive for a given year $(t)$ when a sighting was recorded for this year or the preceding year $(t-1)$.

\section{Data Analyses}

We verified normality of dependent variables and then used general linear mixed models for all variables except for the proportion of breeding adult females, in which case we used a generalized linear model with a binomial distribution and a logit link function (SAS, version 8.2; SAS Institute 1999). Because there was more than one population per island, data from populations were correlated within each island. We accounted for this covariance structure by introducing islands as a random effect in the mixed model and as a repeated subject in the generalized model (SAS Institute 1999). Random effect and repeated subject effect also take into consideration the small sample sizes in some islands. We used linear models to test the relationship of each component of fitness and the per capita population growth rate to fox density (to detect the occurrence of component AEs in per female breeding probability, per female productivity, pup survival, and adult survival, and occurrence of a demographic AE in the per capita population growth rate) and to test the interaction between fox density and eagle presence in each fitness parameter (to detect a predation-driven AE).

An AE would be demonstrated in each demographic trait if it were positively related to population density at low fox density (Courchamp et al. 1999; Stephens \& Sutherland 1999; Liebhold \& Bascompte 2003). Thus, a simple linear and positive relationship between fox density and a fitness parameter would be sufficient to demonstrate the existence of an AE. Nevertheless, our sample covered a broad range of island fox densities, so it is possible that negative density dependence also occurs at high densities (due to intraspecific competition). Both effects
(AE and negative density dependence) can be tested simultaneously by fitting a quadratic function (positive relationship with density and negative relationship with the square of density [Saether et al. 1996; Rohlfs \& Hoffmeister 2003]) of the form

$$
y=a+b D+c D^{2},
$$

where $y$ is a demographic trait (per female breeding probability, per female productivity, adult or juvenile survival, or per capita population growth rate); $D$ is fox density; $a$ is a constant; $b$ scales the linear term of the demographic trait function indicating an $\mathrm{AE}$ when $b>0$; and $c$ scales the quadratic term capturing a curvilinear relationship that results from adding negative density dependence to AEs when $c<0$. We carried out a backward, stepwise elimination of the quadratic term after we determined that the quadratic term was not significant. Thus, final models could contain both terms (AE and negative density dependence, if $b>0$ and $c<0$ ), only the linear term (AE if $b>0$ or negative density dependence if $b<0$ ), or no terms (no density dependence). Fitting a quadratic function allowed us to calculate the densities that maximize each trait (an estimate of the density below which positive density dependence starts to dominate over negative density dependence) and the Allee threshold (an estimate of the density below which the per capita population growth rate becomes negative and populations are likely to decline). We hypothesized that AEs would be more apparent in populations that had undergone a sharp decline or where Golden Eagles were established (i.e., northern island populations). Thus, we carried out two sets of analyses, one with the data combined from all populations and the other with separate analyses for the northern and southern fox populations (specifying a "by" option, SAS Institute 1999). In this way we could assess whether AEs were expressed in all populations or only in the northern populations.

\section{Results}

\section{Density Levels in Island Fox Populations}

We obtained 68 data points for island fox density. Each data point corresponded to a specific population in a specific year (Fig. 2). The data points were distributed in the following manner: 23 for two northern islands distributed in two populations from each island (6 for each population, except for one population of San Miguel with only 5); 45 for three southern islands distributed in three populations from each island (3 for San Nicolas Island, 6 for Santa Catalina Island, and 36 for San Clemente Island).

Mean fox density was significantly lower on the northern islands $\left(\chi^{2}=5.71, p=0.017, n=68\right.$; mean density $[ \pm \mathrm{SD}] 3.97 \pm 4.01$ foxes $/ \mathrm{km}^{2}$ and $6.12 \pm 3.22$ foxes $/ \mathrm{km}^{2}$ for northern and southern islands, respectively). The 
highest fox densities were recorded on a northern island (San Miguel Island, 15.9 foxes $/ \mathrm{km}^{2}$ ) and a southern island (two populations on San Nicolas Island, 16.4 and 16.1 foxes $/ \mathrm{km}^{2}$ ). The lowest densities were recorded on the northern islands in the most recent years (San Miguel and Santa Cruz islands). Northern island populations declined sharply (Fig. 2b) in comparison with southern island populations, although a slight temporal decline was observed in southern islands (Fig. 2c).

\section{AEs in the Island Fox}

When data for all populations were analyzed together, both the proportion of breeding adult females and the number of pups per adult female showed a significant linear relationship with density, but with opposite trends. The proportion of breeding adult females increased with density, which demonstrated a component AE in the probability that a female bred, whereas the number of pups per adult female showed negative density dependence, that is, per capita productivity of adult females was high at low fox density and decreased with increasing density (Table 1; Fig. 3a). Likewise, we detected a significant increase in survival rates with increasing fox density, which revealed the presence of a component $\mathrm{AE}$ in adult and pup survival (Table 1; Figs. 3b-c). Similarly, the per capita population growth rate significantly fitted the linear term of fox density, which revealed a demographic AE (Table 1; Fig. 3d). The lone data point at high density in the northern island populations (Fig. 3) corresponded to the first year of monitoring the Dry Lake Bed grid on San Miguel Island in 1994, when island fox abundance was still high before the decline (Fig. 2b). We removed this point from the analyses because no other estimates were this high and because survival and population growth rates could be overly influenced by the decline in density this grid population experienced the following year. Accounting for this point, however, did not remove the positive and significant relationships between survival and per capita population growth rates and the linear term of fox density that demonstrated an AE.

\section{Predation-Driven AE by the Golden Eagle}

Adult fox survival was significantly related to the interaction between fox density and presence of eagles $(F=$ 6.54, $p=0.015, n=43)$, suggesting that the component AE in adult survival was driven by predation. In the presence of Golden Eagles, adult survival rates were significantly lower at low fox densities than at high fox densities, whereas such a difference did not exist when eagles were absent (Fig. 4). There was no relationship with eagle presence, however, for either the proportion of breeding adult females, pup survival, or per capita population growth rate $\left(\chi^{2}=0.07, p=0.793, n=50 ; F=\right.$ 2.97, $p=0.093, n=43$, and $F=0.34, p=0.560, n=$ 54 , respectively).

\section{AEs in Northern and Southern Island Populations}

Component AEs in adult and pup survival and a consecutive demographic AE occurred only in the northern island fox populations (Table 1; Figs. 3b-d). Component AEs affecting survival and a demographic AE were not expressed in southern populations, where eagles were sporadic and rare visitors. No component AE in reproduction occurred when data from northern and southern islands were analyzed separately (Table 1; Fig. 3a).

Table 1. Effects of island fox density on demographic traits.

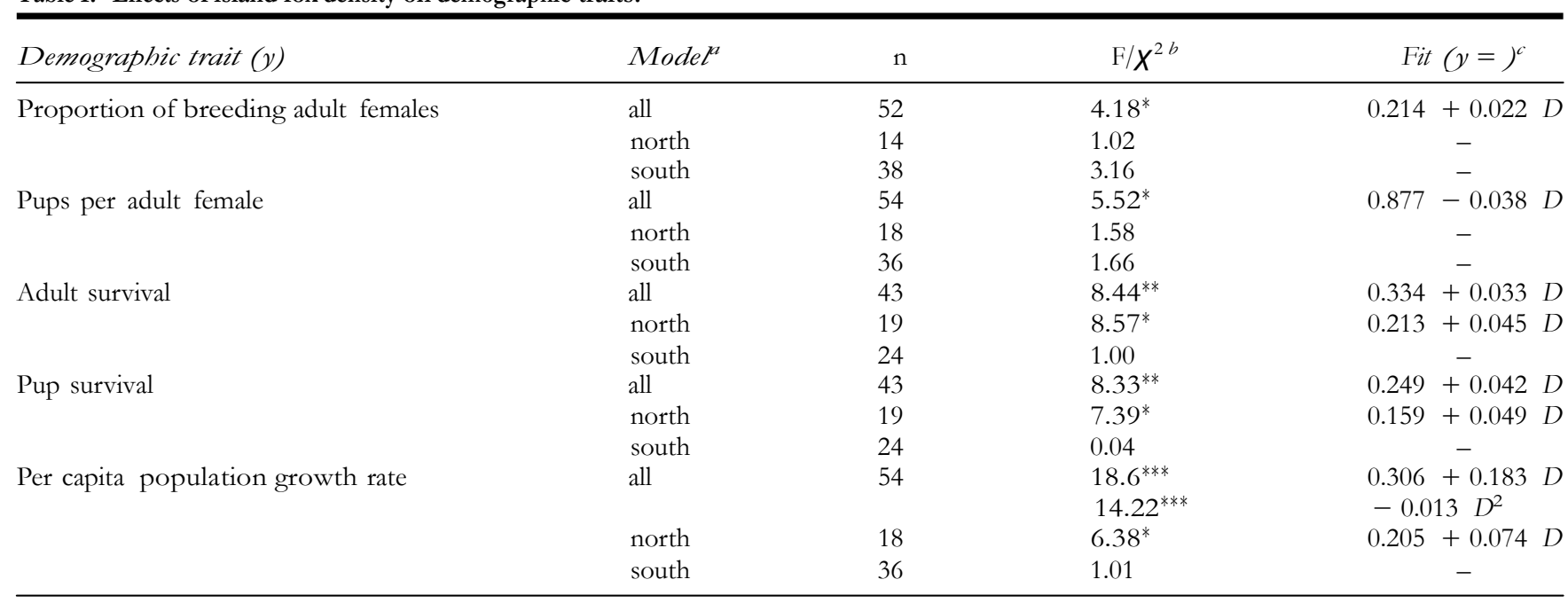

\footnotetext{
a All, north, and south refer to models fitted to data from all populations together, to northern populations only, and to southern populations only, respectively.

${ }^{b}$ The $X^{2}$ is used only for the first demographic trait because of non-normality: ${ }^{*} \mathrm{p}<0.05,{ }^{* *} \mathrm{p}<0.01,{ }^{* * *} \mathrm{p}<0.001$ (others are not significant). ${ }^{c}$ Fits for Eq. 1 are shown only for statistically significant models (D is density).
} 

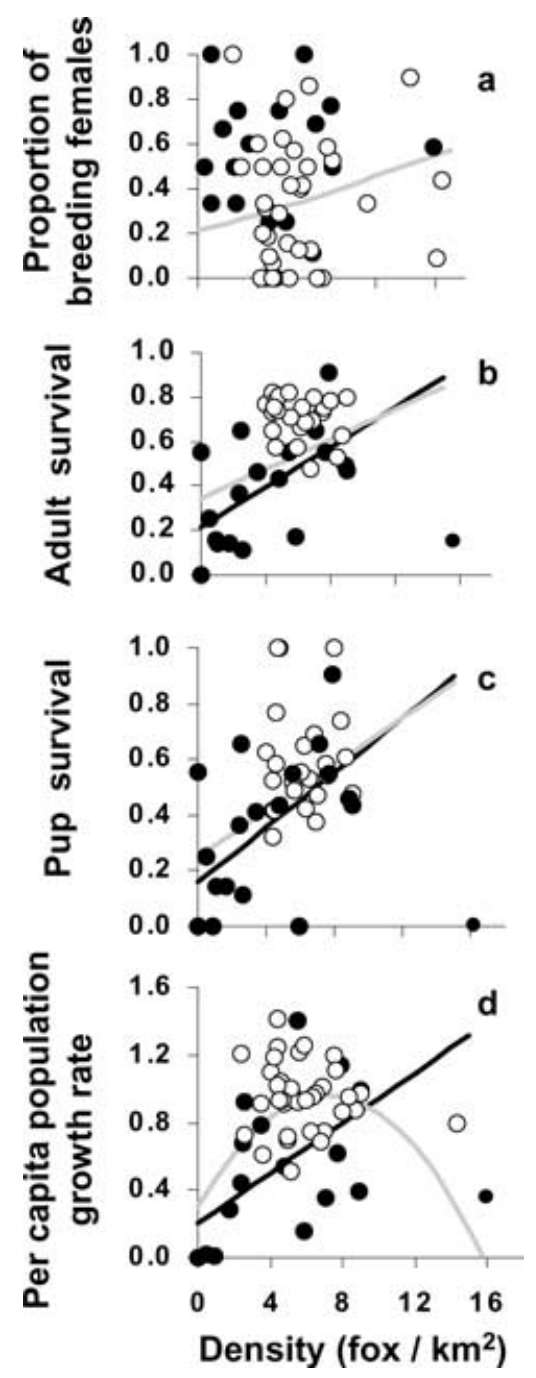

Figure 3. Relationships between demographic traits and density in island fox populations for the northern (black circles) and southern (white circles) California Channel Islands: (a) proportion of breeding adult females, (b) adult survival, (c) pup survival, and (d) per capita population growth rate. Circles are observed values for each population in each year; lines are statistically significant model fits (revealing density dependence) for allpopulations (gray) and for northern populations (black) (see Table 1).

\section{Allee Threshold}

Per capita population growth rates of the fox populations calculated from the fit of the quadratic function (Table 1) were always below 1 (most populations were declining, Figs. 2 \& 3d), precluding quantification of the Allee threshold (the density at which the population growth rate switches from positive to negative values due to a demographic AE). Alternatively, the fox density that maximized each trait was a good indicator of the density at which AEs began to affect the trait negatively. It was pos-

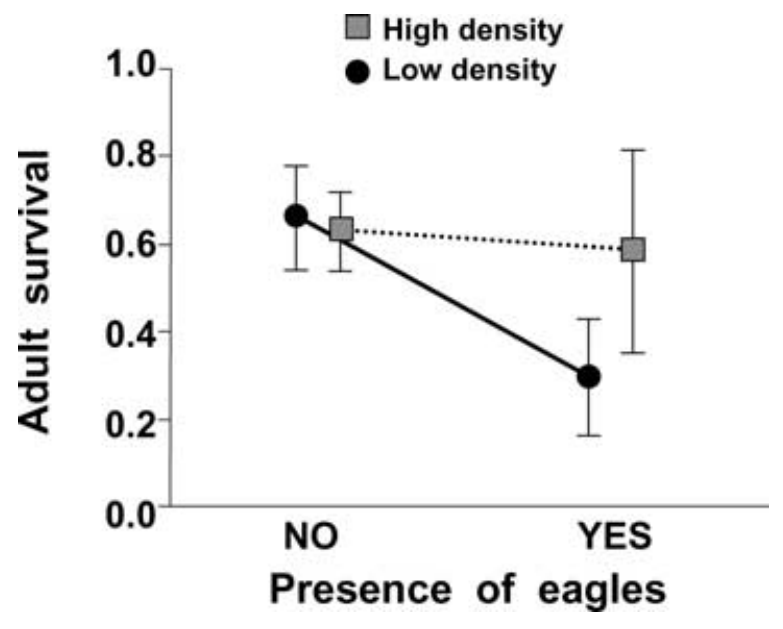

Figure 4. The effect of fox density and Golden Eagle presence on survival of adult island foxes. We categorized fox density as either low or high, with the mean density (5.39 foxes $/ \mathrm{km}^{2}$ ) as the cutoff point between both categories. Vertical bars denote 95\% confidence intervals.

sible to estimate such densities only for those traits for which the fit to the quadratic term of density was significant (i.e., the per capita population growth rate). Pooling data from all islands, the fox density that maximized the per capita population growth rate was 7.14 fox $/ \mathrm{km}^{2}$ (Fig. 3d). This density does not correspond to the Allee threshold; rather, it is the density at which the per capita population growth rate is maximized.

\section{Discussion}

Our results provide empirical evidence for multiple component AEs in an endangered species that together caused a demographic AE. Linking component to demographic AEs is complex because there is a time lag between both types of $\mathrm{AE}$ and because environmental variability could influence and confound any relationship (Stephens et al. 1999). For example, Wittmer et al. (2005) recently showed a demographic AE in the woodland caribou (Rangifer tarandus caribou) and suggested a possible survival-related component $\mathrm{AE}$ that interacts with the geographic location of populations. Nevertheless, the presence of a demographic $\mathrm{AE}$ can be explained by elucidating the mechanism (i.e., by showing the existence of a component AE). Our results showed that there were at least two mechanisms that caused the observed demographic $\mathrm{AE}$ in the island fox: a component $\mathrm{AE}$ in the proportion of breeding females and a component $\mathrm{AE}$ in juvenile and adult survival, the latter driven by Golden Eagle predation.

A component $\mathrm{AE}$ in reproduction has been detected mainly in plants and invertebrates (Avilés \& Tufiño 1998; 
Berggren 2001; Oostermeijer et al. 2003; Gascoigne \& Lipcius 2004b). Its existence has been predicted based on a population model of the alpine marmot (Marmota marmota) (Stephens et al. 2002) and suggested in lemurs (their reproduction seems to be enhanced by the presence of conspecifics [Hearn et al. 1996]). The component $\mathrm{AE}$ in the proportion of breeding females in the island fox is likely a result of species-specific traits related to the mating system (monogamy) and to other intrinsic behavioral characteristics (e.g., territoriality, small home range size, and limited dispersal) (Roemer et al. 2001b). The reduction in the female breeding probability that occurred at low fox densities could be due to the loss of a mate coupled with a decrease in the probability of finding a new mate. In addition, first-year breeders may have more difficulties finding a mate because the distance between territories increases at low density. A reduction in the number of successfully breeding females at low density would reduce competition among females for resources, resulting in more pups being raised per female. This is consistent with the negative density dependence in the number of pups produced per female that we observed (Table 1).

Because it is likely a species-specific trait, we would expect the component $\mathrm{AE}$ in female breeding probability to be expressed in all populations. We could not, however, detect distinct AEs in this fitness trait when data from northern and southern islands were analyzed separately. Two explanations are possible. First, it could be a consequence of the smaller sample size that resulted from separating the two data sets, which may have masked the existing AE. Second, the detection of an AE in southern populations was problematic because the southern populations had globally higher densities than the northern populations and are thus not in the density range where AEs are expressed.

A component $\mathrm{AE}$ in survival has been detected in marine ecosystems, mainly in fishes (Gascoigne \& Lipcius 2004b), but also in arthropods (Rohlfs \& Hoffmeister 2003; Aukema \& Raffa 2004), in relation to some dilution effect. In mammals empirical demonstrations of a component $\mathrm{AE}$ in survival are related to strategies involving cooperative defense, which are more efficient in larger groups. For example, suricates (Suricata suricatta) in areas of high predator density and desert bighorn sheep (Oviscanadensis) exhibit this pattern (Clutton-Brock et al. 1999; Mooring et al. 2004). Nevertheless, a predationdriven $\mathrm{AE}$ can be driven as much by the predator-prey ecology as by prey behavior (Gascoigne \& Lipcius 2004a). Island foxes do not exhibit cooperative defense or any defense against Golden Eagles because avian predators were absent from the island prior to the recent colonization of eagles.

Predation-driven AE occurred only in the northern Channel Islands, where eagles were much more common and bred successfully. Vulnerability of individual foxes to avian predators increased as fox populations became smaller because the number of Golden Eagles present did not fluctuate with fox population size. Consequently, as foxes declined individual predation pressure increased (Fig. 4). Our results have provided the first empirical demonstration of an $\mathrm{AE}$ arising as a consequence of a type II functional response with no numerical response by a predator, validating a possibility that had been predicted theoretically (Cantrell et al. 2001; Gascoigne \& Lipcius 2004a).

Few researchers have identified an AE threshold below which populations are expected to decline. Groom (1998) reported an $\mathrm{AE}$ threshold that shows that as individual plants (of Clarkia concinna [Fish. \& Mey] Greene) become increasingly isolated spatially, reproductive rates drop sharply. Researchers examining the dynamics of introduced insects have also calculated Allee thresholds whereby introduced populations fail once they decline below it (Berggren 2001; Liebhold \& Bascompte 2003). In mammals Allee thresholds have been calculated for group size in relation to a component $\mathrm{AE}$ affecting survival. For example, groups of fewer than five individuals fare less well both in African wild dogs (Lycaon pictus) and in desert bighorn sheep (Courchamp et al. 2002; Mooring et al. 2004). A crucial step for the conservation of the island fox is to determine the threshold density below which per capita population growth rate becomes negative (the Allee threshold), leading to an increased extinction risk (Groom 1998; Berggren 2001; Liebhold \& Bascompte 2003; Johnson et al. 2006). Unfortunately, we were unable to determine an Allee threshold because a declining trend was already the norm for the island fox populations we examined. Hackney and McGraw (2001) show a similar pattern for theoretical projections in the American ginseng (Panax quinquefolius L.). We can, however, suggest that positive density dependence starts working at approximately 7 foxes $/ \mathrm{km}^{2}$. Below this density the per capita population growth rate declined increasingly rapidly (Fig. 3d). This result is of great importance in guiding conservation efforts of the island fox because most populations (northern and southern populations) already had dropped below this density and showed decreasing trends (Figs. 2b-c). Concentrating releases of captive island foxes in small areas to create areas of high fox density may help overcome AEs.

Our main goal was to assess whether the sharp decline of the northern island fox populations of the California Channel Islands could be explained by AEs. We demonstrated that AEs are involved and that these declines are due to a predation-driven $\mathrm{AE}$ in adult fox survival that is caused by Golden Eagles, a novel predator on the northern islands and an uncommon predator on the southern islands. As a result control of Golden Eagles has been advised (Coonan 2001; Roemer et al. 2001a; Courchamp et al. 2003; Roemer et al. 2004) and is under way. Control of Golden Eagles could reduce the strength of the 
demographic AE, thereby protecting currently declining fox populations. Removal of eagles may also increase fox density to the point where the component $\mathrm{AE}$ in the proportion of breeding females would no longer operate. Our results further suggest that the gradual declines observed in the southern island fox populations may require conservation measures. The dramatic impact of double AEs in the northern island fox populations demonstrates that a sharp drop in the southern populations could occur if densities became too low. Indeed, two of these populations (Santa Catalina and San Nicolas islands) recently experienced a dramatic decline (Aguilar et al. 2004; Kohlmann et al. 2005; Clifford et al. 2006), and it is possible that AEs have been involved. More generally, managers need to pay attention to the potential impacts of multiple AEs (Berec et al. 2007) because reduced populations may be closer to extinction than believed if AEs are overlooked.

\section{Acknowledgments}

This work was supported by postdoctoral fellowships from the French Ministry of Research and the Spanish Ministry of Education and Culture (SEEU-FSE) to E.A. L.B. acknowledges funding by the Institute of Entomology (Z50070508) and the Grant Agency of the Academy of Sciences of the Czech Republic (KJB600070602). G.W.R. acknowledges support from the New Mexico Agricultural Experiment Station, the National Geographic Society, the National Park Service, the Nature Conservancy, and the U.S. Navy, and F.C. acknowledges the ANR. T.J. Coonan kindly provided data and J. Laake conducted the survival analysis. We thank P. Amarasekare, A. Angulo, V. Bakker, J. Bascompte, J.A. Blanco, R. Boulay, S. Cabezas, C. Calvete, X. Cerdá, V. Delmas, D. Doak, N. Dulvy, B. Estrada, J. Figuerola, M. Girondot, I. Gomez-Mestre, T. Hoffmeister, A. Oyanguren, and two anonymous referees for their insightful comments.

\section{Literature Cited}

Aguilar, A., G. Roemer, S. Debenham, M. Binns, D. Garcelon, and R. K. Wayne. 2004. High MHC diversity maintained by balancing selection in an otherwise genetically monomorphic mammal. Proceedings of the Royal Academy of Science of the United States of America 101:3490-3494.

Aukema, B. H., and K. F. Raffa. 2004. Does aggregation benefit bark beetles by diluting predation? Links between a group-colonisation strategy and the absence of emergent multiple predator effects. Ecological Entomology 29:129.

Avilés, L., and P. Tufiño. 1998. Colony size and individual fitness in the social spider Anelosimus eximius. The American Naturalist 152:403418.

Berec, L., D. S. Boukal, and M. Berec. 2001. Linking the Allee effect, sexual reproduction, and temperature-dependent sex determination via spatial dynamics. The American Naturalist 157:217-230.

Berec, L., E. Angulo, and F. Courchamp. 2007. Multiple Allee effects and population management. Trends in Ecology \& Evolution 22:185191.
Berggren, A. 2001. Colonization success in Roesel's bushcricket Metrioptera roeseli: the effects of propagule size. Ecology 82:274-280.

Cantrell, R., C. Cosner, and W. F. Fagan. 2001. How predator incursions affect critical patch size: the role of functional response. The American Naturalist 158:368-375.

Clifford, D. L., J. A. K. Mazet, E. J. Dubovi, D. K. Garcelon, T. J. Coonan, P. A. Conrad, and L. Munson. 2006. Pathogen exposure in endangered island fox (Urocyon littoralis) populations: implications for conservation management. Biological Conservation 131:240-243.

Clutton-Brock, T. H., D. Gaynor, G. M. McIlrath, A. D. C. Maccoll, R. Kansky, P. Chadwick, M. Manser, J. D. Skinner, and P. N. M. Brotherton. 1999. Predation, group size and mortality in a cooperative mongoose, Suricata suricatta. Journal of Animal Ecology 68:672683.

Collins, P. W., and B. C. Latta. 2006. Nesting season diet of Golden Eagles on Santa Cruz and Santa Rosa islands, Santa Barbara County, California. Technical report 3. Santa Barbara Museum of Natural History, Santa Barbara, California.

Coonan, T. J. 2001. Recovery plan for island foxes (Urocyon littoralis) on the northern Channel Islands. Channel Islands National Park, Ventura, California.

Coonan, T. J., K. McCurdy, K. A. Rutz, M. Dennis, S. Provinsky, and S. Coppelli. 2005. Island fox recovery program 2004 annual report. Technical report 05-07. Channel Islands National Park, Ventura, California.

Coonan, T. J., and M. Dennis. 2006. Island fox recovery program 2005 annual report. Technical report 06-02. Channel Islands National Park, Ventura, California.

Courchamp, F., T. Clutton-Brock, and B. T.Grenfell. 1999. Inverse density dependence and the Allee effect. Trends in Ecology \& Evolution 14:405-410.

Courchamp, F., G. S. A. Rasmussen, and D. W. Macdonald. 2002. Small pack size imposes a trade-off between hunting and pup guarding in the painted hunting dog Lycaon pictus. Behavioral Ecology 13:2027.

Courchamp, F, R. Woodroffe, and G. W. Roemer. 2003. Removing protected populations to save endangered species. Science 302:1532.

Garcelon, D. K., G. W. Roemer, R. B. Philips, and T. J. Coonan. 1999. Food provisioning by island foxes, Urocyon littoralis, to conspecifics caught in traps. Southwestern Naturalist 44:83-86.

Gascoigne, J. C., and R. N. Lipcius. 2004a. Allee effects driven by predation. Journal of Applied Ecology 41:801-810.

Gascoigne, J., and R. N. Lipcius. 2004b. Allee effects in marine systems. Marine Ecology Progress Series 269:49-59.

Groom, M. J. 1998. Allee effects limit population viability of an annual plant. The American Naturalist 151:487-496.

Hackney, E. E., and J. B. McGraw. 2001. Experimental demonstration of an Allee effect in American ginseng. Conservation Biology 15:129136.

Hearn, G. W., R. W. Berghaier, and D. D. George. 1996. Evidence for social enhancement of reproduction in two Eulemur species. Zoo Biology 15:1-12.

Johnson D. M., A. M. Liebhold, P. C. Tobin, and O. N. Bjornstad. 2006. Allee effects and pulsed invasion by the gypsy moth. Nature 444:361-363.

Kohlmann, S. G., G. A. Schmidt, and K. Garcelon. 2005. A population viability analysis for the Island Fox on Santa Catalina Island, California. Ecological Modelling 183:77-94.

Latta, B. 2005. Channel Islands golden eagle translocation program summary report, 1999-2004. Santa Cruz Predatory Bird Research Group, University of California, Santa Cruz.

Liebhold, A., and J. Bascompte. 2003. The Allee effect, stochastic dynamics and the eradication of alien species. Ecology Letters 6:133140.

Mooring, M. S., T. A. Fitzpatrick, T. T. Nishihira, and D. D. Reisig. 2004. Vigilance, predation risk, and the Allee effect in desert bighorn sheep. Journal of Wildlife Management 68:519-532. 
Oostermeijer, J. G. B., S. H. Luitjten, and J. C. M. denNijs. 2003. Integrating demographic and genetic approaches in plant conservation. Biological Conservation 113:389-398.

Roemer, G. W. 1999. The ecology and conservation of the island fox. Ph.D. thesis. University of California, Los Angeles.

Roemer, G. W., P. S. Miller, J. Laake, C. Wilcox, and T. J. Coonan. 2000. Island fox demographic workshop report. Final report. Channel Islands National Park, Ventura, California.

Roemer, G. W., T. J. Coonan, D. K. Garcelon, J. Bascompte, and L. Laughrin. 2001a. Feral pigs facilitate hyperpredation by Golden Eagles and indirectly cause the decline of the island fox. Animal Conservation 4:307-318.

Roemer, G. W., D. A. Smith, D. K. Garcelon, and R. K. Wayne. 2001b. The behavioural ecology of the island fox (Urocyon littoralis). Journal of Zoology 255:1-14.

Roemer, G. W., C. J. Donlan, and F. Courchamp. 2002. Golden Eagles, feral pigs, and insular carnivores: how exotic species turn native predators into prey. Proceedings of the Royal Academy of Science of the United States of America 99:791-796.

Roemer, G. W., R. Woodroffe, and F. Courchamp. 2004. Predators and prey in the Channel Islands-response. Science 305:778.

Rohlfs, M., and T. S. Hoffmeister. 2003. An evolutionary explanation of the aggregation model of species coexistence. Proceedings of the Royal Society of London, B 270:S33-S35.

Saether, B. E., T. H. Ringsby, and E. Roskaft. 1996. Life history variation, population processes and priorities in species conservation: towards a reunion of research paradigms. Oikos 77:217-226.

SAS Institute. 1999. User's guide. Version 8. SAS Institute, Cary, North Carolina.

Stephens, P. A., and W. J Sutherland. 1999. Consequences of the Allee effect for behaviour, ecology and conservation. Trends in Ecology \& Evolution 14:401-405.

Stephens, P. A., W. J. Sutherland, and R. P. Freckleton. 1999. What is the Allee effect? Oikos 87:185-190.

Stephens, P. A., F. Frey-Roos, W. Arnold, and W. J Sutherland. 2002. Model complexity and population predictions. The alpine marmot as a case study. Journal of Animal Ecology 71:343-361.

Swarts, H. M. 2006. Annual Integrated Fox Recovery Team meeting summary. Department of Wildlife, Fish, and Conservation Biology, University of California, Davis.

White, G. C., and J. P. Burnham. 1997. Program MARK-survival estimation from populations of marked animals. Colorado State University, Fort Collins. Available from http://www.warnercnr.colostate.edu/ $\sim$ gwhite/software.html (accessed November 2006).

Wilson, K. R., and D. R. Anderson. 1985. Evaluation of two density estimators of small mammal population size. Journal of Mammalogy 66:13-21.

Wittmer, H. U., A. R. E. Sinclair, and B. N. McLellan. 2005. The role of predation in the decline and extirpation of woodland caribou. Oecologia 144:257-267.

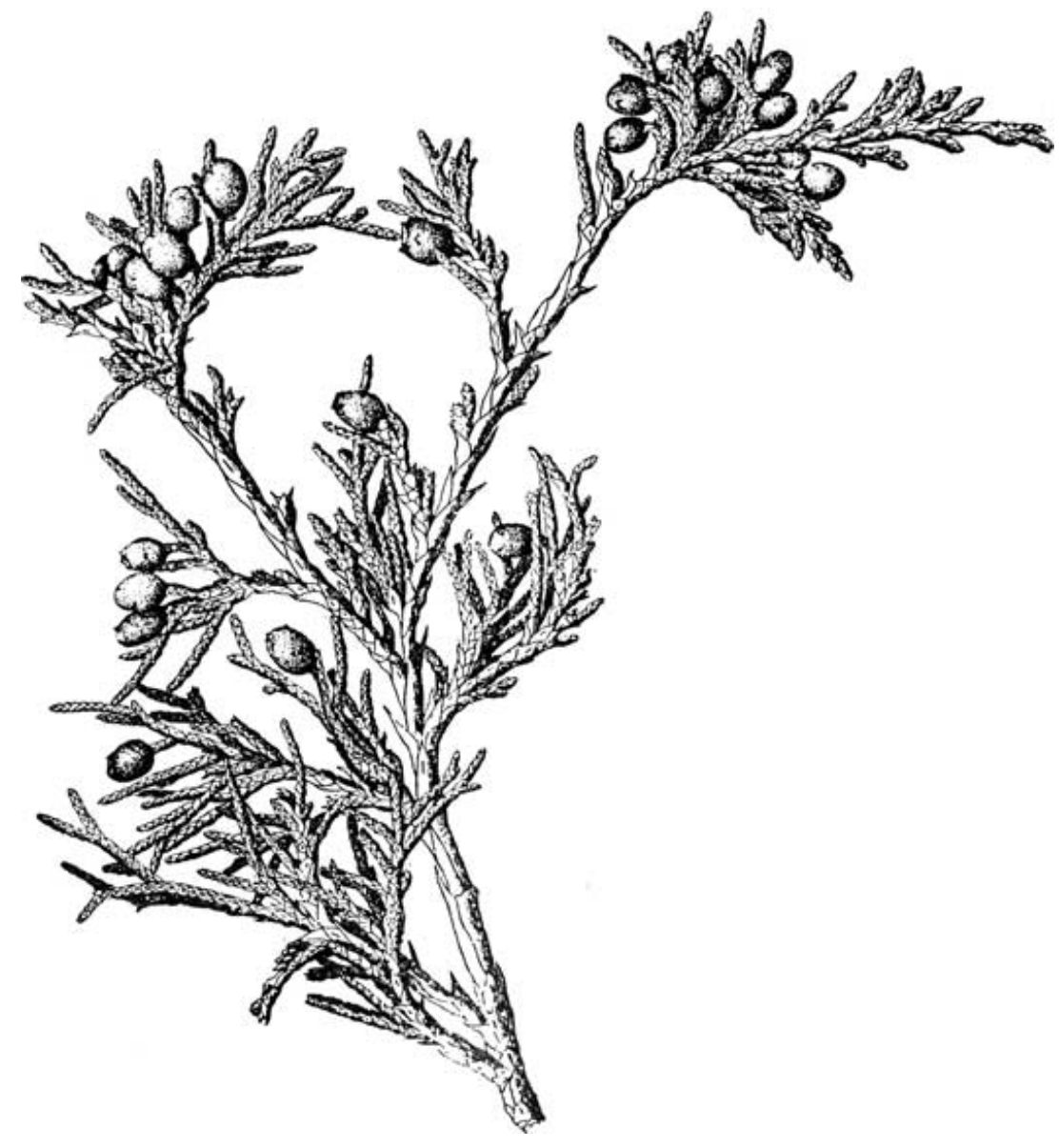

